\title{
Acute Toxicity, Phytochemical Screening, Analgesic, and Anti-Inflammatory Activities of Aqueous and Methanol Root Extracts of Maerua triphylla A. Rich. (Capparaceae)
}

\author{
Brian Muyukani Wangusi $\mathbb{D}^{1},{ }^{1}$ Laetitia Wakonyu Kanja, ${ }^{1}$ Isaac Mpapuluu Ole-Mapenay, \\ and Jared Misonge Onyancha $\mathbb{D}^{2}$ \\ ${ }^{1}$ Department of Public Health, Pharmacology and Toxicology, College of Veterinary and Agricultural Sciences, \\ University of Nairobi, P.O. Box 29053-00625, Nairobi, Kenya \\ ${ }^{2}$ Department of Pharmacognosy, College of Health Sciences, Mount Kenya University, P.O. Box 342-01000, Thika, Kenya
}

Correspondence should be addressed to Brian Muyukani Wangusi; bwangusi@students.uonbi.ac.ke

Received 12 August 2021; Revised 21 October 2021; Accepted 26 October 2021; Published 15 November 2021

Academic Editor: Yongbo Xue

Copyright ( $) 2021$ Brian Muyukani Wangusi et al. This is an open access article distributed under the Creative Commons Attribution License, which permits unrestricted use, distribution, and reproduction in any medium, provided the original work is properly cited.

\begin{abstract}
Maerua triphylla root extracts are used by Maasai and Kikuyu communities in Kenya to manage headaches, stomachaches, migraines, and rheumatism. However, scientific data on their safety and efficacy are limited. The current study aims to investigate the safety, phytochemical constituents, analgesic, and anti-inflammatory activities of M. triphylla root extracts. Aqueous and methanol $M$. triphylla root extracts were prepared by cold maceration, and the extracts' safety was evaluated using Wistar rats according to the Organization for Economic Cooperation and Development (2008) guidelines. Standard qualitative phytochemical screening methods were used for the detection of various phytochemical groups in the extracts. Analgesic activity assay in Swiss albino mice was done using the acetic acid-induced writhing test, while anti-inflammatory activity was determined in Wistar rats using the acetic acid-induced paw edema method. The methanol and aqueous extracts revealed $\mathrm{LD}_{50}>2000 \mathrm{mg} / \mathrm{kg}$ bw, classifying them as nontoxic. The presence of cardiac glycosides, flavonoids, alkaloids, and phenols was observed in both extracts. However, saponins were only present in the methanol extract. In the analgesic study, mice that received $100 \mathrm{mg} / \mathrm{kg} \mathrm{bw}$ and $500 \mathrm{mg} / \mathrm{kg}$ bw of aqueous root extract of $M$. triphylla had significantly lower acetic acid-induced writhing than mice that received acetylsalicylic acid $75 \mathrm{mg}$ (reference drug) $(p<0.05)$. Additionally, mice that received $500 \mathrm{mg} / \mathrm{kg}$ bw of methanol root extract of M. triphylla had significantly lower acetic acid-induced writhing than mice that received the acetylsalicylic acid $75 \mathrm{mg}(p<0.05)$. In the anti-inflammatory study, there was no significant difference $(p<0.05)$ between the inhibitory activity of different doses of the aqueous root extract of $M$. triphylla and a $50 \mathrm{mg} / \mathrm{kg}$ dose of diclofenac sodium (reference drug) on acetic acid-induced paw edema in rats. Moreover, there was no significant difference in the inhibitory activity of $100 \mathrm{mg} / \mathrm{kg}$ bw and $500 \mathrm{mg} / \mathrm{kg} \mathrm{bw} \mathrm{doses} \mathrm{of}$ the methanol root extract of $M$. triphylla and a $50 \mathrm{mg} / \mathrm{kg}$ dose of diclofenac sodium on acetic acid-induced paw edema $(p>0.05)$. These findings suggest that the roots of $M$. triphylla may be useful in the safe mitigation of pain and inflammation and therefore support their ethnomedicinal use in the management of pain and inflammation.
\end{abstract}

\section{Introduction}

Pain is an unwanted emotional or receptive sensation localized to a part of the body. It is often described in terms of penetrative or tissue-destructive process like stabbing, burning, tearing, and squeezing [1]. Bradykinin, prostaglandins, and histamine are the major mediators of pain. On the other hand, inflammation is the body's normal, protective response to tissue injury caused by physical trauma, noxious chemicals, or microbiologic agents, which is a part of the host defense [2]. Inflammation usually subsides on completion of the healing process, but sometimes it turns to be severe and may be fatal, leading to diseases such as arthritis, rheumatism, and cancer $[3,4]$. The treatment of such 
diseases generally relies on a large number of commercial preparations, including nonsteroidal anti-inflammatory drugs (NSAIDs), corticosteroids, and opioid analgesics [5]. However, most of these drugs have adverse effects like peptic ulcer, dyspepsia, and gastrointestinal bleeding [6]. Furthermore, these drugs are costly and have low efficacy [7]. Therefore, a large number of medicinal plants need to be investigated for their alternative use as analgesic and antiinflammatory agents.

M. triphylla (Capparaceae) is an evergreen shrub growing to a height of up to 3 meters above ground. The roots of $M$. triphylla have been used to treat conditions like rheumatism, headache, migraine, diarrhea, and stomachache by the Maasai and Kikuyu communities in Kenya [8]. However, there is insufficient scientific data to support this ethnomedicinal use of $M$. triphylla roots in management of pain and inflammatory conditions. Moreover, the safety of using the root extracts from $M$. triphylla is unknown [8]. The current study assessed acute oral toxicity, phytochemical groups, pain-relieving, and anti-inflammatory properties of M. triphylla root extracts.

\section{Materials and Methods}

2.1. Plant Materials. Fresh roots of $M$. triphylla were obtained from Kajiado County, Ilbisil area, with the assistance of a renowned local herbalist. Identification and authentication of the prepared specimen were done by a plant taxonomist at the Department of Land Resource Management and Agricultural Technology (LARMAT), University of Nairobi. The voucher specimen number LARMATCAP36 was assigned to the specimen. The collected roots of $M$. triphylla were cleaned with running water, cut into small pieces, air-dried in a well-ventilated room for 14 days, and crushed into coarsely powdered material using an electric grinder. The powder was kept in a well-labeled manila sack and kept in a cool and nonhumid place awaiting extraction.

\subsection{Extraction Methods}

2.2.1. Methanol Extract. Extraction was done according to the procedure described in [9] and later modified in [10]. In summary, $250 \mathrm{~g}$ of the root powder was soaked in 1 liter of analytical grade methanol using a 1.8-liter conical flask and then covered with a foil paper with constant shaking for 48 hours to macerate. This procedure was repeated for another batch of 250 grams of the root powder. The resultant mixture was then decanted and filtered through a cotton gauze, and the filtrate was further filtered through a Whatman No. 1 filter paper. The resultant filtrates were combined and reduced in vacuo at $50^{\circ} \mathrm{C}$ using a rotary evaporator. Thereafter, the extract was transferred into a clean, dry, and light- resistant glass bottle and placed in a sand bath set at $35^{\circ} \mathrm{C}$ to further remove the solvent and concentrate the extract. The actual weight of the dried extract was measured using an analytical balance and recorded before it was stored at $4^{\circ} \mathrm{C}$ in a refrigerator pending biological assay.

2.2.2. Aqueous Extract. About $250 \mathrm{~g}$ of the M. triphylla root powder was cold macerated in 1.25 liters of distilled water in a 1.8-liter conical flask and then covered with a foil paper with constant shaking for 24 hours. This procedure was repeated for another batch of $250 \mathrm{~g}$ of the root powder. The resulting mixtures were decanted and filtered through a Whatman No. 1 filter paper. The resultant filtrates were then lyophilized using a freeze-dryer. The obtained freeze-dried product was weighed using an analytical balance, and the weight was recorded before being stored in tightly closed, light-resistant bottles at $4^{\circ} \mathrm{C}$ in a refrigerator pending biological assay [10].

2.3. Experimental Animals. In this study, both male and female Wistar rats (8-10 weeks old, weighing $110 \pm 20 \mathrm{~g}$ ) obtained from the animal house of the Department of Public Health, Pharmacology and Toxicology (PHPT) of the University of Nairobi (UoN) were used to assess the acute oral toxicity and anti-inflammatory activities of $M$. triphylla root extracts. Both male and female Swiss albino mice (4-5 weeks old, weighing $30 \pm 5 \mathrm{~g}$ ) obtained from the animal breeding facility at Veterinary Farm Kabete were used to assess the analgesic activities of $M$. triphylla root extracts. The experimental mice were delivered to the animal house of the department of PHPT of the University of Nairobi (UoN) and were allowed to acclimatize for seven days before the beginning of the experiment.

All the experimental animals were nulliparous and nonpregnant. The animals were housed in polypropylene cages in standard laboratory conditions. Tap water and standard laboratory animal pellets were provided ad libitum. Animal use and care guidelines outlined by the Faculty of Veterinary Medicine Biosafety, Animal Use and Ethics Committee (BAUEC) of the University of Nairobi and the National Council for Science, Technology and Innovation (NACOSTI) were adhered to in this study.

2.4. Preparation of Administration Doses. In this study, the Organization for Economic Cooperation and Development [11] (Document No. 425) standards in [12] were followed in the preparation of the doses for administration. Shortly, to make a stock solution with a dosage level of $500 \mathrm{mg} / \mathrm{kg}$ bw for administration to a rat weighing $100 \mathrm{~g}$, the following formula described in [12] was followed:

$$
\operatorname{animal~dose~}(\mathrm{mg} / \mathrm{kg} \mathrm{bw})=\frac{\text { bodyweight of the animal }(\mathrm{g}) \times \text { selected dose }}{1000 \mathrm{~g}} .
$$


Therefore, animal dose $(\mathrm{mg} / \mathrm{kg} \mathrm{bw})=(100 \mathrm{~g} / 1000 \mathrm{~g})$
$\times 500 \mathrm{mg}=50 \mathrm{mg}$.
In accordance with the Organization for Economic In accooperation and Development [11] (Document No. 425) guidelines, $50 \mathrm{mg}$ should be reconstituted in $0.2 \mathrm{ml}$ of the physiological saline (vehicle). In this study, a $10 \mathrm{ml}$ stock solution containing $500 \mathrm{mg} / \mathrm{kg}$ bw of either the aqueous or the methanol root extracts of $M$. triphylla was prepared and serially diluted with physiological saline to generate dosages of $100 \mathrm{mg} / \mathrm{kg}$ bw and $20 \mathrm{mg} / \mathrm{kg}$ bw doses. Similarly, this procedure was followed for the reference drug.

2.5. Acute Oral Toxicity Effects of M. triphylla Aqueous and Methanol Extracts. To investigate the safety of the aqueous and methanol extracts of M. triphylla, the Up-and-Down procedure for acute oral toxicity described by Organization for Economic Cooperation and Development [11] (Document No. 425) was used. The female Wistar rats were randomly assigned to three groups of five (5) rats each. Each animal was individually weighed and labeled with a permanent marker on its tail. They fasted overnight before the commencement of the study. The limit test was conducted by administering an oral single dose of $2000 \mathrm{mg} / \mathrm{kg}$ bw aqueous and methanol root extract of $M$. triphylla to Group I and Group II, respectively. Group III was treated as negative control and was administered with physiological saline orally. Thereafter, wellness parameters such as mortality, lethargy, salivation, mucous membrane appearance, skin, hair, diarrhea, unconsciousness, changes in body weight, and sleep were observed and documented in 30 minutes, 1 hour, 4 hours, 24 hours, 48 hours, 7 days, and 14 days correspondingly.

2.6. Phytochemical Screening of M. triphylla Root Aqueous and Methanol Extracts. The presence of common groups of phytoconstituents was detected in $M$. triphylla root aqueous and methanol extracts using the methods described by Harborne [13] and Kokate et al. [14] with modification. Froth test was used to detect saponins and Dragendorff's test for alkaloids; the flavonoids were revealed by the alkaline reagent test. Ferric chloride test was used to evaluate the presence of phenolic compounds and tannins. The existence of cardiac glycosides, steroids, and terpenoids was assessed by the Keller-Kilian test for cardiac glycosides and the Salkowski test was used for steroids and terpenoids.

2.7. In Vivo Analgesic Activity of M. triphylla Root Aqueous and Methanol Extracts. The analgesic effects of the aqueous and methanol root extracts of $M$. triphylla were evaluated using the acetic acid-induced writhing procedure developed by [15] in Swiss albino mice of either sex. The mice were randomly assigned to five groups ( $\mathrm{V}, \mathrm{W}, \mathrm{X}, \mathrm{Y}$, and $\mathrm{Z}$ ), with each group consisting of 5 animals. Groups $\mathrm{V}$ and $\mathrm{W}$ received $300 \mu \mathrm{l}$ physiological saline and $75 \mathrm{mg} / \mathrm{kg}$ bw acetylsalicylic acid orally as negative and positive controls, respectively. Groups X, Y, and Z on the other hand received an oral treatment of $20 \mathrm{mg} / \mathrm{kg} \mathrm{bw}, 100 \mathrm{mg} / \mathrm{kg}$ bw, and
$500 \mathrm{mg} / \mathrm{kg}$ bw, respectively, of the aqueous and methanol root extracts of $M$. triphylla. After a half-hour, writhing was induced in each mouse with a $200 \mu 0.6 \% \mathrm{v} / \mathrm{v}$ acetic acid injection intraperitoneally.

Five minutes after writhing induction, the animals were individually observed and counting of the number of writhes was done for a half-hour and documented. The mean count of writhes and the percentage inhibition of writhing was determined as an index of analgesic activity using the formula defined by Rashid et al. [15]:

$$
\text { percentage writhing inhibition }=\frac{\left(W_{c}-W\right)}{W_{c}} \times 100,
$$

where $W_{c}$ is the mean number of writhes in the negative control group and $W$ is the mean number of writhes in the positive control and experimental group.

2.8. Determination of the Anti-Inflammatory Effects of M. triphylla Root Aqueous and Methanol Extracts. The antiinflammatory activity of $M$. triphylla root extracts was evaluated using $0.6 \% \mathrm{v} / \mathrm{v}$ acetic acid as the inflammationinducing agent and diclofenac sodium as the reference drug. The experimental rats of either sex were randomly divided into five groups ( $\mathrm{V}, \mathrm{W}, \mathrm{X}, \mathrm{Y}$, and $\mathrm{Z}$ ), with each group having 5 rats. Evaluation of the anti-inflammatory activity was carried out as described by Winter et al. [16]. The diameter of the intact rat's right hind paw was measured in millimeters in all groups using a digital vernier caliper and recorded. Groups V and $\mathrm{W}$ received $1.5 \mathrm{ml}$ physiological saline and $50 \mathrm{mg} / \mathrm{kg}$ bw diclofenac sodium orally as negative and positive controls, respectively. Groups $\mathrm{X}, \mathrm{Y}$, and $\mathrm{Z}$ on the other hand received an oral treatment of $20 \mathrm{mg} / \mathrm{kg} \mathrm{bw}$, $100 \mathrm{mg} / \mathrm{kg}$ bw, and $500 \mathrm{mg} / \mathrm{kg}$ bw, respectively, of M. triphylla root aqueous and methanol extracts. Two hundred microliters of $0.6 \% \mathrm{v} / \mathrm{v}$ acetic acid was then injected into the subplantar tissue of the right hind paw 30 minutes after administration of the treatments to induce edema.

After inflammation induction, the diameter of the right hind paw was measured hourly from the first hour up to the fifth hour. Paw diameter measured prior to the acetic acid injection was then compared with the diameter of the same paw after acetic injection by calculating the percentage inhibition and percentage change using the formula described by Omowumi et al. [17]:

$$
\text { percentage inhibition of oedema }=\frac{\left(T-T_{0}\right)}{T} \times 100,
$$

where $T$ is the thickness of paw in the negative control group and $T_{0}$ is the thickness of paw in the experimental and negative control group.

2.9. Statistical Data Management and Analysis. The data obtained from analgesic and anti-inflammatory activities were tabulated on Microsoft Excel spreadsheet (2016), expressed as Mean \pm Standard Error of the Mean (SEM), and analyzed using analysis of variance (ANOVA) and the twosample $t$-test by GenStat statistical software 4 th edition. This 
was followed by Tukey's post hoc test for pairwise comparison and separation of means at $\alpha=0.05$. Values with $p \leq 0.05$ were considered statistically significant. Acute oral toxicity data were quantitatively and qualitatively analyzed according to Organization for Economic Cooperation and Development [11] guidelines (Document No. 425), and the $\mathrm{LD}_{50}$ value was recorded.

2.10. Ethical Considerations. Permission to conduct the current study was obtained from the Faculty of Veterinary Medicine Biosafety, Animal Use and Ethics Committee (BAUEC) of the University of Nairobi with a permit reference number FVM BAUEC/2021/291. The research license for the study was also obtained from the National Commission for Science, Technology, and Innovation (NACOSTI) with a license number NACOSTI/P/21/9494.

\section{Results}

3.1. Acute Oral Toxicity Effects of M. triphylla Root Extracts. The observations from acute oral toxicity studies of aqueous and methanol M. triphylla root extracts revealed the absence of signs of toxicity and lethal effects in Wistar rats at the limit/cut-off dose of $2000 \mathrm{mg} / \mathrm{kg}$ bw. The doses that could be lethal to half of the experimental rats $\left(\mathrm{LD}_{50}\right.$ values) for M. triphylla root aqueous and methanol extracts were thus observed to be above $2000 \mathrm{mg} / \mathrm{kg}$ bw. Therefore, the extracts were classified as nontoxic according to the OECD 425 guidelines.

3.2. Phytochemical Screening. The results from the study indicated that $M$. triphylla root aqueous and methanol extracts contain alkaloids, flavonoids, cardiac glycosides, and phenolic compounds. Saponins were revealed only in methanol extract and were absent in the aqueous extract. Tannins, steroids, and terpenoids were not observed in both the aqueous and methanol extracts of $M$. triphylla root (Table 1).

3.3. In Vivo Analgesic Effects of the Aqueous and Methanolic Root Extracts of M. triphylla. Below is a summary of the effect of the aqueous and methanol root extracts of M. triphylla on acetic acid-induced writhing in mice. The effects are compared with those of $75 \mathrm{mg} / \mathrm{kg}$ bw dose of acetylsalicylic acid (reference drug).

In this study, the aqueous and methanol root extracts of M. triphylla inhibited acetic acid-induced writhing in mice in a dose-dependent manner (Table 2). However, there was no significant difference in the effect of a $75 \mathrm{mg} / \mathrm{kg}$ bw dose level of acetylsalicylic acid and a $20 \mathrm{mg} / \mathrm{kg}$ bw dose level of the aqueous $M$. triphylla root extract on acetic acid-induced writhing in mice ( $p>0.05$; Table 2). Conversely, the $100 \mathrm{mg} /$ $\mathrm{kg}$ bw and $500 \mathrm{mg} / \mathrm{kg}$ bw dose levels of the aqueous root extract of $M$. triphylla produced a significantly higher inhibition of acetic acid-induced writhing than a $75 \mathrm{mg} / \mathrm{kg}$ bw dose level of acetylsalicylic acid $(p<0.05$; Table 2$)$.
TABle 1: Phytochemical composition of $M$. triphylla root aqueous and methanol extracts.

\begin{tabular}{lcc}
\hline Phytochemical & Aqueous extract & Methanol extract \\
\hline Saponins & - & + \\
Alkaloids & + & + \\
Terpenoids & - & - \\
Flavonoids & + & + \\
Cardiac glycosides & + & + \\
Steroids & - & - \\
Phenols & + & + \\
Tannins & - & - \\
\hline
\end{tabular}

+: present; -: absent.

On the other hand, the inhibition of acetic acid-induced writhing by a $75 \mathrm{mg} / \mathrm{kg}$ dose of acetylsalicylic acid was not significantly different from the inhibition resulting from the use of $20 \mathrm{mg} / \mathrm{kg}$ bw and $100 \mathrm{mg} / \mathrm{kg}$ bw dose levels of the methanol root extract of $M$. triphylla ( $p>0.05$; Table 2). However, the use of a $500 \mathrm{mg} / \mathrm{kg}$ bw dose level of the methanol root extract of $M$. triphylla produced a significantly higher inhibition of acetic acid-induced writhing than the use of $75 \mathrm{mg} / \mathrm{kg}$ bw dose level of acetylsalicylic acid $(p<0.05$; Table 2).

This study also included a comparison of M. triphylla root extract effects on acetic acid-induced writhing in mice (Figure 1).

The results showed that, at all dose levels, the mice that received the aqueous root extract of $M$. triphylla showed significantly higher percentage inhibition of the acetic acidinduced writhing than that recorded for mice that received the methanol root extract $(p<0.05$; Figure 1).

\subsection{In Vivo Anti-Inflammatory Effects of M. triphylla Root Aqueous and Methanol Extracts}

3.4.1. Effect of M. triphylla Root Aqueous and Methanol Extracts Treatment on Acetic Acid-Induced Paw Edema in Wistar Rats. Table 3 is a summary of the effect of aqueous and methanol root extracts of $M$. triphylla on acetic acidinduced paw edema in rats. The effects are compared with those of $50 \mathrm{mg} / \mathrm{kg}$ bw dose of diclofenac sodium (reference drug).

The results showed that there was no significant difference $(p>0.05)$ between the effect of different doses of the aqueous root extract of $M$. triphylla and a $50 \mathrm{mg} / \mathrm{kg}$ dose of diclofenac sodium on acetic acid-induced paw edema in rats (Table 3).

Conversely, the mice that received the methanolic root extract demonstrated significantly increased percentage inhibition of acetic acid-induced paw edema in rats in a dose-dependent fashion ( $p<0.05$; Table 3$)$. A low dose of the methanol extract of $M$. triphylla produced a significantly lower $(p<0.05)$ inhibition of acetic acid-induced paw edema than a $50 \mathrm{mg} / \mathrm{kg}$ dose of diclofenac (Table 3). There was no significant difference in the inhibitory activity of intermediate and high doses of the methanol extract of $M$. triphylla and a $50 \mathrm{mg} / \mathrm{kg}$ dose of diclofenac sodium on acetic acidinduced paw edema (Table 3). 
TABLe 2: Effect of M. triphylla root aqueous and methanol extract on acetic acid-induced writhing in Swiss albino mice.

\begin{tabular}{lcccc}
\hline \multirow{2}{*}{ Dose $(\mathrm{mg} / \mathrm{kg} \mathrm{bw})$} & \multicolumn{2}{c}{$\begin{array}{c}\text { Aqueous root extract } \\
\text { \% writhing inhibition }\end{array}$} & Mean number of writhes & \multicolumn{2}{c}{ Methanol root extract } \\
& Mean number of writhes & \% wing inhibition \\
\hline 20 & 13.00 & $85.31 \pm 1.13^{\mathrm{a}}$ & 15.80 & $81.84 \pm 1.51^{\mathrm{a}}$ \\
100 & 5.80 & $93.43 \pm 1.26^{\mathrm{b}}$ & 10.00 & $88.43 \pm 1.25^{\mathrm{bc}}$ \\
500 & 3.60 & $95.97 \pm 1.16^{\mathrm{b}}$ & 6.20 & $92.55 \pm 1.20^{\mathrm{c}}$ \\
ASA $(75 \mathrm{mg} / \mathrm{kg} \mathrm{bw})$ & 16.60 & $81.08 \pm 1.16^{\mathrm{a}}$ & 15.60 & $82.17 \pm 2.11^{\mathrm{ab}}$ \\
Physiological saline & 88.20 & 0 & 88.00 & 0 \\
\hline
\end{tabular}

Values are presented as mean \pm SEM. Means with different superscript letters along the same column are significantly different (one-way ANOVA and Tukey's test; $p<0.05)$. ASA: acetylsalicylic acid.

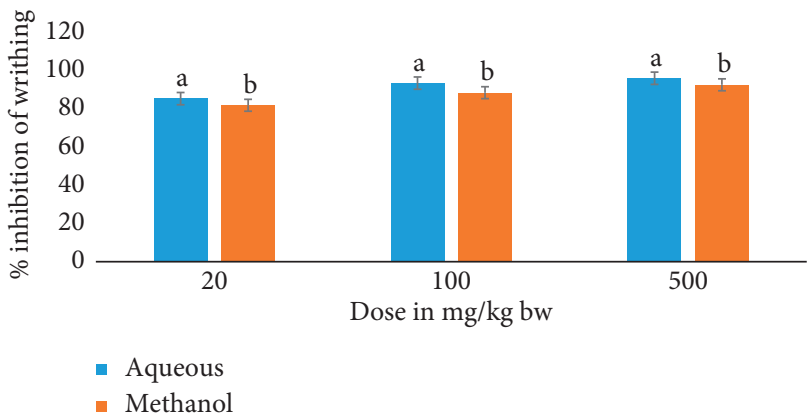

Figure 1: A comparison of the analgesic activities of aqueous and methanol root extracts of $M$. triphylla in Swiss albino mice. Bars are plotted as mean \pm SEM. Bars with different superscript letters within the same dose level are significantly different (two-sample $t$ test; $p<0.05)$.

TABLE 3: Summary of the effect of the aqueous and methanol extracts of M. triphylla on acetic acid-induced paw edema in Wistar rats.

\begin{tabular}{lcc}
\hline \multirow{2}{*}{ Treatment (mg/kg bw) } & \multicolumn{2}{c}{ \% inhibition of edema } \\
& Aqueous extract & Methanol extract \\
\hline Diclofenac sodium (50) & $24.23 \pm 7.78^{\mathrm{a}}$ & $29.81 \pm 5.76^{\mathrm{bc}}$ \\
20 & $9.11 \pm 5.79^{\mathrm{a}}$ & $7.57 \pm 5.01^{\mathrm{a}}$ \\
100 & $17.48 \pm 5.20^{\mathrm{a}}$ & $19.77 \pm 6.46^{\mathrm{ab}}$ \\
500 & $28.63 \pm 6.21^{\mathrm{a}}$ & $47.69 \pm 6.57^{\mathrm{c}}$ \\
\hline
\end{tabular}

Values are presented as mean \pm SEM. Means with different superscript letters along the same column are significantly different from each other (two-way ANOVA and Tukey's test; $p<0.05$ ).

3.4.2. Effect of Duration of Treatment on Acetic Acid-Induced Paw Edema in Wistar Rats. Table 4 is a summary of the effect of duration of treatment on acetic acid-induced paw edema in rats.

Figure 2 further illustrates the onset and duration of action of $M$. triphylla root extracts in inhibiting acetic acidinduced paw edema in Wistar rats.

The duration of treatment did not significantly affect the efficacy of the aqueous extract of $M$. triphylla to inhibit acetic acid-induced paw edema in rats ( $p<0.5$; Table 4 and Figure 2). Conversely, the inhibition of acetic acid-induced paw edema in rats treated with the methanol extract was significantly higher $(p<0.05)$ after 3,4 , and 5 hours relative to after 1 hour (Table 4 and Figure 2). Moreover, there was no significant difference $(p>0.05)$ in the inhibition of acetic acid-induced paw edema
TABLE 4: Effects of the duration of treatment on acetic acid-induced paw edema in Wistar rats.

\begin{tabular}{lcc}
\hline \multirow{2}{*}{ Duration } & \multicolumn{2}{c}{$\%$ inhibition of edema } \\
& Aqueous extract & Methanol extract \\
\hline 1 hour & $16.63 \pm 7.70^{\mathrm{a}}$ & $6.83 \pm 10.32^{\mathrm{a}}$ \\
2 hours & $27.65 \pm 3.12^{\mathrm{a}}$ & $12.89 \pm 4.86^{\mathrm{ab}}$ \\
3 hours & $13.22 \pm 6.52^{\mathrm{a}}$ & $39.61 \pm 3.87^{\mathrm{c}}$ \\
4 hours & $11.92 \pm 8.17^{\mathrm{a}}$ & $38.34 \pm 6.27^{\mathrm{c}}$ \\
5 hours & $29.90 \pm 8.57^{\mathrm{a}}$ & $33.37 \pm 7.05^{\mathrm{bc}}$ \\
\hline
\end{tabular}

Values are presented as mean \pm SEM. Means with different superscript letters along the same column are significantly different (two-way ANOVA and Tukey's test $p<0.05$ ).

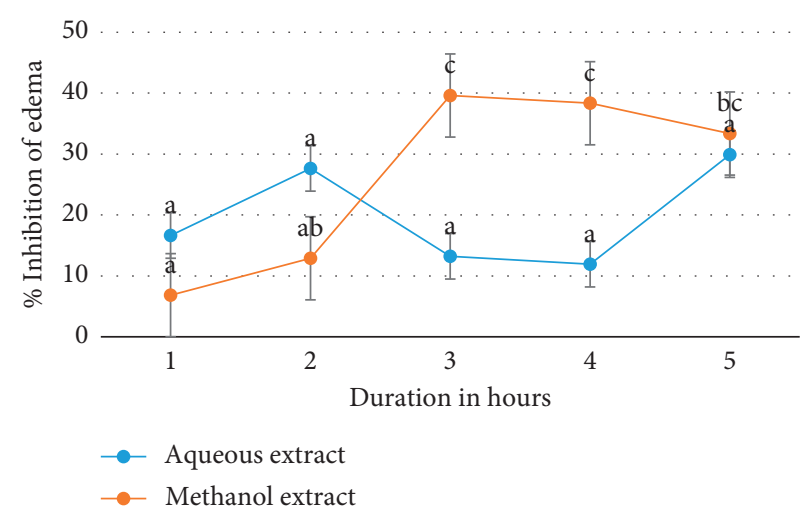

FIgURE 2: Effects of the duration of treatment on acetic acid-induced paw edema in Wistar rats. Values are presented as mean\pm SEM. Means with different superscript letters along the same line are significantly different (two-way ANOVA followed by Tukey's test; $p<0.05)$.

in rats treated with the methanol extract after 2 hours relative to after 1 hour (Table 4 and Figure 2).

3.4.3. Effect of Treatment and Duration on the Acetic AcidInduced Paw Edema in Wistar Rats. There was no significant difference $(p>0.05)$ between the effect of low, intermediate, and high doses of the aqueous root extract of M. triphylla and the effect of diclofenac sodium on acetic acid-induced paw edema in rats after 1, 2, 3, 4, and 5 hours. However, the percentage inhibition of acetic acid-induced paw edema in rats treated with a low dose of the methanol root extract of $M$. triphylla after 1 hour was significantly lower $(p<0.05)$ than that in rats treated with a high dose after 3,4 , and 5 hours. 


\section{Discussion}

The present study evaluated acute oral toxicity, phytochemical content, and the analgesic and anti-inflammatory properties of the aqueous and methanol root extracts of M. triphylla. The widespread use of $M$. triphylla as a source of traditional medicine throughout its distributional range suggests that the species is not taken at toxic dosages. However, the FDA and WHO emphasize the validation of efficacious and safe use of herbal therapies through the conduction of scientific-based studies [18, 19]. Therefore, rigorous toxicological and clinical studies of the leaves, fruits, bark, roots, and compounds isolated from the species are necessary [8] to determine their safer dose range [20].

In this study, the acute oral toxicity effects of both the aqueous and methanol root extracts of $M$. triphylla were determined using the Up-and-Down procedure described by Organization for Economic Cooperation and Development [11] (Document No. 425). This procedure has also been used in previous studies $[21,22]$. There were no observable signs of toxicity in the experimental rats at the cut-off dose of $2000 \mathrm{mg} / \mathrm{kg}$ bw, suggesting that the extracts are nontoxic at therapeutic doses. This study disagrees with previous findings of Hamilton and Hamilton [23] and Dharani [24] that found out that the roots of $M$. triphylla have to be boiled for a long time to render them nontoxic. The toxicity here however could be due to repeated intake of the M. triphylla root porridge, hence requiring subacute or chronic toxicity assay.

According to Husna et al. [25], the absence of observable signs of toxicity and mortality in animals treated with a particular test dose implies that the $\mathrm{LD}_{50}$ is greater than the test dose. No morbidity or mortality was observed in any of the animals during the entire period of the study, suggesting that the $\mathrm{LD}_{50}$ of the aqueous and methanol root extracts of M. triphylla was above $2000 \mathrm{mg} / \mathrm{kg}$ bw. Previous studies have shown that the presence of toxic secondary metabolites like alkaloids is responsible for the adverse side effects reported when some plants or their products have been consumed [26]. These results, therefore, suggest that the studied plant extracts either lack the toxic metabolites or are present in too low concentrations to cause any observable signs of toxicity.

The phytochemical screening method of Harborne [13] and Kokate et al. [14] used in this study to qualitatively screen for phytoactive compounds in the plant extracts revealed the presence of cardiac glycosides, flavonoids, alkaloids, and phenols in both extracts, which is in agreement with previous studies [27]. Both extracts tested negative for terpenoids, steroids, and tannins. No saponins were present in the aqueous extract as opposed to the methanol extract that tested positive for saponins. This is in agreement with previous studies where the investigators established that not all phytochemicals may be found in plant parts [28].

Bioactive compounds such as flavonoids, alkaloids, saponins, phenols, and cardiac glycosides found in the extracts have been found to possess analgesic and anti-inflammatory properties in previous studies. Numerous studies have shown that alkaloids possess analgesic and anti-inflammatory properties $[29,30]$. Flavonoids also show analgesic and anti-inflammatory activity by inhibiting prostaglandin synthetase, which in turn reduces prostaglandin synthesis and release [31-33]. Cardiac glycosides suppress hypersecretion of IL-8, a protein implicated in lung inflammation, thus inhibiting the activation of the NF- $\beta$ signaling pathway. Phenols lower the expression and inhibit the function of iNOS. They also reduce the level of inflammatory mediators like TNF- $\alpha$ and prostaglandins [34].

The evaluation of the analgesic properties of the extracts of $M$. triphylla was determined using the acetic acid-induced writhing technique on Swiss albino mice of either sex. This technique is normally selected as a standard procedure to evaluate the peripheral analgesic efficacy of natural products and drugs and act by stimulating chemically induced stimulus [35]. The intraperitoneal injection of acetic acid induces the release of endogenous mediators such as prostaglandin, especially prostaglandin 2, histamine, bradykinin, and serotonin in peritoneal fluids. This produces peritoneal inflammation, which is associated with pain $[36,37]$. This pain is characterized by abdominal muscle contractions, body elongation, and extension of forelimbs characterized as writhing whose frequency can be quantified [21]. Agents that inhibit or reduce the acetic acid-induced writhing frequency are considered as having an analgesic effect.

In this study, both the aqueous and methanol root extracts of $M$. triphylla demonstrated significant inhibition of the acetic acid-induced writhing in mice. Pain sensation in the acetic acid-induced writhing method is brought about by triggering localized inflammatory response resulting from the release of free arachidonic acid from tissue phospholipid [38] via cyclooxygenase and prostaglandin biosynthesis in peritoneal fluids [39]. Furthermore, other pain mediators like bradykinins and histamine are released from cells lining the peritoneal cavity and further help stimulate nociceptors. The increase in prostaglandin levels within the peritoneal cavity then enhances inflammatory pain by increasing capillary permeability [40]. These results suggest that the extracts were able to inhibit the prostaglandin synthesis, which is an inflammatory pain mediator. It can therefore be suggested that the flavonoids and alkaloids contained in the aqueous and methanolic root extracts of $M$. triphylla could be responsible for the analgesic effect of the extracts. This is similar to other results obtained in previous studies that have examined the analgesic activities of other medicinal plants [41].

The aqueous extract was more potent than the methanol extract throughout the dose levels. This suggests that the aqueous extract contains more active compounds responsible for the analgesic effect compared to the methanol extract at similar dose levels. The three dose levels of both the aqueous and methanol root extracts of $M$. triphylla produced a dose-dependent response to the acetic-induced pain. This kind of response was also observed by [21]. Peak analgesic effect was observed at a dose of $500 \mathrm{mg} / \mathrm{kg}$ in both extracts with the analgesic effect of both extracts being greater than that of the reference drug acetylsalicylic acid $(75 \mathrm{mg} / \mathrm{kg} \mathrm{bw})$ at all dose levels except for methanol extract at a dose of $20 \mathrm{mg} / \mathrm{kg}$ bw. This could be explained by the fast metabolism 
and clearance of the active compounds that were in an insufficient concentration in the lower dose level of the methanol extract [1].

Inflammation is a normal, protective response to tissue injury caused by physical trauma, noxious chemicals, or microbiologic agents, which is a part of the host defense [2]. Some of the symptoms that characterize inflammation include the release of inflammatory mediators, vasodilation, increased blood flow, necrosis, tissue degeneration, and formation of exudates. Inflammation usually subsides on completion of the healing process, but sometimes it turns to severe, which may be fatal, leading to varying degrees of tissue injuries, diseases such as arthritis, and even death [3].

In this experiment, the anti-inflammatory properties of aqueous and methanol root extracts of M. triphylla in Wistar rats of either sex were investigated using acetic acid-induced paw edema. The subplantar injection of acetic acid induces the release of inflammatory mediators such as serotonin and histamine [37]. Therefore, there is increased vasculature permeability with greater vasodilation resulting in edema at the paw [37]. An increase in paw size is used to quantify the inflammatory response seen after acetic acid injection.

The results obtained in this study suggest a remarkable ability of the aqueous and methanol root extracts of M. triphylla in inhibiting acetic acid-induced paw edema in rats. NSAIDs alleviate inflammation by inhibiting the activity of phospholipase $\mathrm{A}_{2}$ and COX-2 [42]. Flavonoids, cardiac glycosides, phenols, and saponins have been reported in other studies to also have potent anti-inflammatory properties $[33,34]$. Therefore, the flavonoids, cardiac glycosides, and phenols identified in both extracts could be responsible for the anti-inflammatory activity of the plant extracts by inhibiting prostaglandin synthesis in a similar manner to NSAIDs. The methanol extract had better percentage inhibition of inflammation than the aqueous extract of the same plant at the intermediate and high dose levels. A similar kind of response was also observed by $[43,44]$. Apart from flavonoids, cardiac glycosides, and phenols, saponins were identified in the methanol extract but were absent in the aqueous extract. In previous studies, 3,4-seco-dammarane triterpenoid saponins isolated from Cyclocarya paliurus leaves have exhibited anti-inflammatory activity. This suggests that the saponins in the methanol root extract of $M$. triphylla could be responsible for the better potency of the methanol extract in inhibiting inflammation in comparison to the aqueous extract [45].

Peak anti-inflammatory effect was observed at a dose of $500 \mathrm{mg} / \mathrm{kg}$ in both extracts, with both extracts exhibiting a dosedependent relationship. Similar results have also been observed by [21]. The anti-inflammatory effect of the aqueous extracts was not significantly different from the reference drug diclofenac sodium at all doses. This could imply that the concentration of the phytochemicals responsible for the anti-inflammatory activity of the aqueous extract was similar at all the studied doses. In the methanol extract, however, only the low methanol extract dose had a lower anti-inflammatory activity than the standard drug. This could be explained by the fast metabolism and clearance of the active compounds that were in an insufficient concentration in these lower dose levels of the extract [1].
The three doses of the aqueous extract and methanol extract together with their respective standard drugs (diclofenac sodium) achieved maximum anti-inflammatory activity in the second and third hours, respectively. This indicates a gradual but steady passive diffusion of the bioactive phytochemicals across the cell membrane into the site of inflammation [46]. This would suggest that the aqueous extract constituents diffused faster than the methanol extract constituents, hence achieving the maximal anti-inflammatory effect at the second hour rather than the third hour in the methanol extract. From the results, the aqueous extract at the three dose levels had low percentage inhibition of the acetic acid-induced paw edema in rats during the first hour. The methanol extract at the three dose levels had low percentage inhibition of the acetic acid-induced paw edema in rats during the first and second hours. This can be explained by the absence of prostaglandins in this early phase of inflammation since the treatments were working similarly to NSAIDs by inhibiting the biosynthesis of prostaglandins [42].

Previous studies have identified betaines and quaternary ammonium compounds such as 3-hydroxyproline betaine, glycine betaine, proline betaine, and 3-hydroxy-1,1-dimethyl pyrrolidinium from dried aerial parts and branches of M. triphylla [47]. Proline betaine has been shown to significantly suppress IL- $1 \beta$-induced inflammation with decreased levels of inflammatory mediators and cytokines, including NO, PGE2, iNOS, COX-2, TNF- $\alpha$, and IL-6 [48]. This compound has also been shown to dock at the COX-2 receptor using GOLD docking fitness and therefore inhibiting the activity of the COX-2 enzyme [49]. This suggests that proline betaine could be responsible for the analgesic and anti-inflammatory properties of the $M$. triphylla root extracts.

\section{Conclusion}

Based on the results obtained in this study, it was concluded that the aqueous and methanolic root extracts of $M$. triphylla have significant analgesic and anti-inflammatory effects, which may be due to the presence of phytochemicals such as flavonoids. In addition, both the aqueous and methanol root extracts of $M$. triphylla are nontoxic at therapeutic levels. Therefore, the aqueous and methanol $M$. triphylla root extracts may be used in the mitigation of pain and inflammation, as claimed in ethnomedicine.

However, isolation, characterization, and quantification of the specific phytochemical constituents in the M. triphylla root extracts with analgesic and anti-inflammatory activity is required. Moreover, future studies should focus on determining the specific analgesic and anti-inflammatory mechanism(s) of action of the M. triphylla root extracts at cellular and molecular levels. Additionally, apart from acute toxicity, evaluation of the subacute and chronic effects of the $M$. triphylla root extracts in experimental animal models should be done.

\section{Data Availability}

All data are available within the manuscript, and additional data are available from the corresponding authors upon request. 


\section{Conflicts of Interest}

The authors declare that there are no conflicts of interest exist regarding this publication.

\section{Authors' Contributions}

Jared Onyancha conceived the research idea. Brian Wangusi performed the experiments, analyzed the data, and drafted the manuscript. Laetitia Kanja and Isaac Mapenay supervised the entire study. All authors reviewed and approved the final manuscript for publication.

\section{Acknowledgments}

The authors would like to acknowledge the Department of Public Health, Pharmacology and Toxicology of the University of Nairobi for providing the lab facility, model animals, reagents, and equipment for this study. Mr. Maloba and Mr. Asava of the Department of Public Health, Pharmacology and Toxicology (UoN) are appreciated for their technical assistance. This research and publication were funded by Brian Muyukani Wangusi.

\section{References}

[1] G. S. Maina, J. K. Kelvin, M. B. Maina et al., "Antinociceptive properties of dichloromethane: methanolic leaf and root bark extracts of Carissa edulis in rats," Journal of Phytopharmacology, vol. 4, no. 2, pp. 106-112, 2015.

[2] S. Stankov, "Definition of inflammation, causes of inflammation and possible anti-inflammatory strategies," The Open Inflammation Journal, vol. 5, no. 1, pp. 1-9, 2012.

[3] F. Richard, A. C. Michelle, and X. C. Luigi, Lippincott's Illustrated Reviews: Pharmacology, Lippincott Williams \& Wilkins, Philadelphia, 4th edition, 2008.

[4] A. Burke, E. Smyth, and G. A. Fitz-Gerald, "Analgesic-antipyretic agents; pharmacotherapy of gout," in Goodman \& Gilman's the Pharmacological Basis of Therapeutics, L. L. Brunton, J. S. Lazo, and K. L. Parker, Eds., McGraw-Hill, New York, NY, USA, 11th edition, 2006.

[5] B. G. Katzung, Basic and Clinical Pharmacologypp. 643-644, McGraw-Hill, Lange, 14th edition, 2018.

[6] P. McGettigan, "Cardiovascular risk with non-steroidal antiinflammatory drugs: systematic review of population-based controlled observational studies," PLoS Medicine, vol. 8, no. 9, pp. 1-18, 2011.

[7] M. I. G. Amaral, M. R. Silva, P. F. Aquino-Neto et al., "Biologica and," Pharmaceutical Bulletin, vol. 30, pp. 12-17, 2007.

[8] M. Alfred, "Evaluation of ethnomedicine and ethnobotany of Maerua triphylla A. Rich. (Capparidacae)," International Journal of Research in Pharmacy and Science, vol. 11, no. 4, pp. 6196-6202, 2020.

[9] J. B. Harborne, Phytochemical Methods: A Guide to Modern Techniques of Plant Analysis, Cox \& Wyman Ltd., Fakenham, Norfolk, 1976.

[10] Y. Bibi, S. Nisa, M. Zia, A. Waheed, S. Ahmed, and F. M. Chaudhary, "The study of anticancer and antifungal activities of Pistacia integerrima extract in vitro," Indian Journal of Pharmaceutical Sciences, vol. 74, no. 4, pp. 375-379, 2012.
[11] Organisation for Economic Cooperation and Development (OECD), Test No. 425: Acute Oral Toxicity: Up-And-Down Procedure, OECD Guidelines for the Testing of Chemicals, Paris, France, Section 4, 2008.

[12] E. Erhierhie, N. Oghenesuvwe, E. Ekene, and A. L. Daniel, "Guidelines on dosage calculation and stock solution preparation in experimental animals' studies," Journal of Natural Sciences Research, vol. 4, no. 18, pp. 100-106, 2014.

[13] J. B. Harborne, Phytochemical Methods: A Guide to Modern Techniques of Plant Analysis, Chapman and Hal Publishers, London, UK, 1998.

[14] C. K. Kokate, A. P. Purohit, and S. B. Gokhale, Pharmacognosypp. 108-109, 39th edition, 2007.

[15] M. H. Ur Rashid, S. Biswas, M. Abdullah-Al-Mamun, A. Huque, and J. R. Bhuiyan, "Phytochemical screening and analgesic, anti-bacterial and cytotoxic activity evaluation of ethanol extract of Pithcellobium dulce (Roxb.) benth leaf," Asian Journal of Pharmaceutical and Clinical Research, vol. 8, no. 2, pp. 451-457, 2015.

[16] C. A. Winter, E. A. Risley, and G. W. Nuss, "Carrageenaninduced edema in hind paw of the rat as an assay for antiinflammatory drugs," Experimental Biology and Medicine, vol. 111, no. 3, pp. 544-547, 1962.

[17] O. A. Omowumi, N. A. God'swill, and O. Odutola, "Aqueous fraction of Alstonia boonei de wild leaves suppressed inflammatory responses in carrageenan and formaldehyde induced arthritic rats," Biomedicine \& Pharmacotherapy, vol. 86, pp. 95-101, 2017.

[18] R. W. Setzer and C. A. Kimmel, "Use of NOAEL, benchmark dose, and other models for human risk assessment of hormonally active substances," Pure and Applied Chemistry, vol. 75, no. 11-12, pp. 2151-2158, 2003.

[19] World Health Organization, Research Guidelines for Evaluating the Safety and Efficacy of Herbal Medicines Page 94, World Health Organization, Geneva, Switzerland, 1993.

[20] U. Saleem, B. Ahmad, M. Ahmad, A. Erum, K. Hussain, and N. I. Bukhari, "Is folklore use of euphorbia helioscopia devoid of toxic effects?" Drug and Chemical Toxicology, vol. 39, no. 2, pp. 233-237, 2016.

[21] B. Olela, J. Mbaria, T. Wachira, and G. Moriasi, “Acute oral toxicity and anti-inflammatory and analgesic effects of aqueous and methanolic stem bark extracts of piliostigma thonningii (schumach)," Evidence-Based Complementary and Alternative Medicine, vol. 2020, Article ID 5651390, 10 pages, 2020.

[22] U. Saleem, S. Amin, B. Ahmad, H. Azeem, F. Anwar, and S. Mary, "Acute oral toxicity evaluation of aqueous ethanolic extract of Saccharum munja Roxb. roots in albino mice as per OECD 425 TG," Toxicology Reports, vol. 4, no. March, pp. 580-585, 2017.

[23] A. Hamilton and A. Hamilton, Plant Conservation: An Ecosystem Approach, Earthscan, London, UK, 2006.

[24] N. Dharani, Field Guide to Common Trees and Shrubs of East Africa, Struik Nature, Cape Town, South Africa, 2019.

[25] R. N. Husna, A. Noriham, H. Nooraain, A. H. Azizah, and O. F. Amna, "Acute oral toxicity effects of Momordica charantia in sprague dawley rats," International Journal of Bioscience Biochemistry and Bioinformatics, vol. 3, no. 4, pp. 408-410, 2013.

[26] R. J. Molyneux, S. T. Lee, D. R. Gardner, K. E. Panter, and L. F. James, "Phytochemicals: the good," The Bad and the Ugly Phytochemistry, vol. 68, no. 22-24, pp. 2973-2985, 2007.

[27] L. E. Kers, "Flowering plants dicotyledons," Capparaceae, vol. 242, no. 1789, pp. 36-56, 2003. 
[28] O. M. Otieno, "Prophylactic efficacy of moringa oleifera leaf extracts against liver injury induced by artesunate-amodiaquine antimalarial combination," 2016, https://pdfs. semanticscholar.org/a43a/ de746a9e094c5b0b8bde5dfe6bfe8cc6d6c1.pdf.

[29] B. Chindo, J. Anuka, E. Isaac, A. Ahmadu, F. Tarfa, and K. Gamaniel, "Saponins are involved in the analgesic and antiinflammatory properties of Ficus platyphylla stem bark," International Journal of Brain and Cognitive Sciences, vol. 4, no. 2, pp. 415-423, 2010.

[30] W. Kaleem, N. Muhammad, M. Qayum et al., "Antinociceptive activity of cyclopeptide alkaloids isolated from Ziziphus oxyphylla Edgew (Rhamnaceae)," Fitoterapia, vol. 91, pp. 154-158, 2013.

[31] H. M. Hossinzadeh, M. Ramezani, M. Fedishei, and B. K. Mahmoudi, "Anti-nociceptive, anti- inflammatory and acute toxicity effects of Zzhumeria majdae extracts in mice and rats," Phytomedicine, vol. 9, pp. 135-141, 2002.

[32] A. Chatterjee, B. Sen, S. Das, and T. K. Chatterjee, "Antiinflammatory and analgesic activity of methanolic extract of medicinal plant Rhodiola rosea rhizomes," International Journal of Pharmacy Review and Research, vol. 4, no. 2, pp. 1-8, 2015.

[33] A. R. Tapas, D. M. Sakarkar, and R. B. Kakde, "Flavonoids as nutraceuticals: a review," Tropical Journal of Pharmaceutical Research, vol. 7, no. 3, pp. 1089-1099, 2008.

[34] D. W. Nyamai, W. Arika, P. E. Ogola, E. N. M. Njagi, and M. P. Ngugi, "Medicinally important phytochemicals: an untapped research avenue," Journal of Pharmacognosy and Phytochemistry, 2016.

[35] J. Zhen, Y. Guo, and T. Villani, "Phytochemical analysis and anti-inflammatory activity of the extracts of the African medicinal plant Ximenia caffra," Journal of Analytical Methods in Chemistry, vol. 2015, Article ID 948262, 9 pages, 2015.

[36] A. Bose, S. Mondal, J. K. Gupta, T. Ghosh, G. K. Dash, and S. Si, "Analgesic, anti-inflammatory and antipyretic activities of the ethanolic extract and its fractions of Cleome rutidosperma," Fitoterapia, vol. 78, no. 7, pp. 515-520, 2007.

[37] N. Yasmen, A. Aziz, A. Tajmim, M. I. Akter, A. K. Hazra, and S. M. M. Rahman, "Analgesic and anti-inflammatory activities of diethyl ether and N-hexane extract of Polyalthia suberosa leaves," Evidence-based Complementary and Alternative Medicine, vol. 20188 pages, 2018.

[38] A. Bhattacharya, S. Kumar, S. Mishra, S. Patnaik, P. Sahu, and D. Agrawal, "Analgesic effect of ethanolic leaf extract of Moringa oleifera on albino mice," Indian Journal of Pain, vol. 28, no. 2, pp. 89-94, 2014.

[39] S. Gupta and A. Singh, "Antimicrobial, analgesic and antiinflammatory activity reported on Tamarindus indica Linn Root extract," Pharmacognosy Journal, vol. 9, no. 3, pp. 410-416, 2017.

[40] Z. A. Zakaria, Z. D. F. Abdul-Ghani, M. Raden, R. N. S. Nor, H. K. Gopalan, and M. R. Sulaiman, "Antinociceptive, antiinflammatory, and antipyretic properties of an aqueous extract of Dicranopteris linearis leaves in experimental animal models," Journal of Natural Medicines, vol. 62, pp. 179-187, 2008.

[41] V. Z. Safari, M. P. Ngugi, G. Orinda, and E. M. Njagi, "Antipyretic, anti-inflammatory and analgesic activities of aqueous stem extract of Cynanchum viminale (L.) in albino mice," Medicinal \& Aromatic Plants, vol. 5, no. 2, p. 36, 2016.

[42] J. Necas and L. Bartosikova, "Carrageenan: a review," Veterinary Medicine, vol. 58, pp. 187-205, 2013.
[43] M. Uddin, M. Rana, S. Hossain et al., "In vivo neuroprotective, antinociceptive, anti-inflammatory potential in Swiss albino mice and in vitro antioxidant and clot lysis activities of fractionated Holigarna longifolia Roxb. bark extract," Journal of Complementary and Integrative Medicine, vol. 17, no. 1, 2020.

[44] Y. H. Hong, J. H. Kim, and J. Y. Cho, "Ranunculus bulumei methanol extract exerts anti-inflammatory activity by targeting src/syk in NF- $\kappa$ B signaling," Biomolecules, vol. 10, no. 4, p. $546,2020$.

[45] W. Liu, S. Deng, D. Zhou et al., "3,4-seco-Dammarane triterpenoid saponins with anti-inflammatory activity isolated from the leaves of Cyclocarya paliurus," Journal of Agriculture and Food Chemistry, vol. 68, no. 7, pp. 2041-2053, 2020.

[46] E. Hossain, S. C. Mandal, and J. K. Gupta, "Phytochemical screening and in-vivo antipyretic activity of the methanol leafextract of Bombax malabaricum DC (Bombacaceae)," Tropical Journal of Pharmaceutical Research, vol. 10, no. 1, pp. 55-60, 2011.

[47] W. F. McLean, G. Blunden, and K. Jewers, "Quaternary ammonium compounds in the Capparaceae," Biochemical Systematics and Ecology, vol. 24, no. 5, pp. 427-434, 1996.

[48] W. Haojie, Z. Minghui, L. Weihua, Z. Shutao, and $Z$. Dengfeng, "Stachydrine attenuates IL- $1 \beta$-induced inflammatory response in osteoarthritis chondrocytes through the NF- $\kappa \mathrm{B}$ signaling pathway," Chemico-Biological Interactions-Elsevier, vol. 326, Article ID 109136, 2020.

[49] N. M. M. Uddin, B. T. Emran, R. M. M. Mahib, and R. Dah, "Molecular docking and analgesic studies of Erythrina variegata's derived phytochemicals with COX enzymes," Bio Information, vol. 10, no. 10, pp. 630-636, 2014. 